\title{
Perceived Antecedents to The Success of Impact Sourcing in Bangladesh
}

\section{Saeed Uz Zaman Khan}

University of Technology Sydney

Sydney, New South Wales

Email: Saeed.U.Khan@student.uts.edu.au

\section{Sojen Pradhan}

School of Information, Systems and Modelling

University of Technology Sydney

Sydney, New South Wales

Email: Sojendra.Pradhan@uts.edu.au

\begin{abstract}
Impact sourcing (ImS) has been identified as an emergent component of Business Process Outsourcing (BPO) which relates to the practice of developing IT skills for marginalised communities. Also known as socially responsible outsourcing, the core element of $\operatorname{ImS}$ is to train and employ people from disadvantaged background in expediting socioeconomic development. While the positive influence of ImS has been significantly noticed in countries such as India, Kenya and Nepal, there has not been any appropriate initiatives noticed in one of the most promising nations, Bangladesh. With adequate IT and telecommunication foundation followed by strong governmental support, Bangladesh has the potential to flourish in ImS sector and make significant socioeconomic development for its people. This research in progress paper proposes a conceptual framework to understand the perceived antecedents for adopting ImS undertakings in Bangladesh and provide valuable insight to the government and researchers/practitioners for employing effective ICT based social development strategies.
\end{abstract}

\section{Keywords}

Impact Sourcing, Outsourcing, Social Innovation, Socioeconomic development, Bangladesh. 


\section{Introduction}

Impact sourcing (ImS) has been identified as an emergent component of the global Information Technology (IT) and Business Process Outsourcing (BPO) field which focuses on the skill development for the marginalized communities (Malik et al. 2013; Porter \& Kramer 2011). While the traditional definition of BPO underlines the practice of sending work to external organizations (Beaumont \& Sohal 2004), impact sourcing aims to create employment through Information and Communications Technology (ICT) for disadvantaged people living in areas of limited developmental opportunities (Monitor Group 2011; Selim 2013).

Sandeep and Ravishankar (2016) highlighted impact sourcing as an incipient social innovation in BPO due to the relative newness and scarce research (Pradhan 2017; Sandeep \& Ravishankar 2015) on how impact sourcing service providers (ISSPs) surface and the process through which social entrepreneurs build and operate such companies. ISSPs act as intermediaries between the outsourcing client and BPO employees and assist in the service delivery process through training and recruitment (Kennedy et al. 2013). Rockefeller Foundation and other researchers (Carmel et al. 2016; Heeks \& Arun 2010; Lacity et al. 2014; Malik et al. 2013) has made significant contributions to develop the ImS sector worldwide and increase awareness regarding its benefit towards the disadvantaged population. Nevertheless, within the BPO industry, impact sourcing and its potential benefits for socioeconomic development and social innovation has not been widely recognized (Sandeep \& Ravishankar 2016; Kennedy et al. 2013).

In the context of developing countries, ICT has often been viewed as a mediator of GDP growth, socioeconomic development, employment and poverty alleviation (Kozma 2005; Irawan 2014). The impact of globalization and technological advancement in restructuring the labour force and creating employment opportunities has been well documented in the context of developed countries (Selim 2013). However, this effect is also equally visible amongst emerging economies such as India, Bangladesh, Nepal, and Kenya as increasing usage of smartphone, computing devices and access to the internet is equipping individuals with necessary skill in a cost effective way and linking them to potential employers (Accenture 2012; Selim 2013). For instance, over 60 million people in Bangladesh has access to mobile internet (Hussain \& Mostafa. 2016).

Coined as one of the most promising destination for impact sourcing sector (Avasant 2012) therefore, Bangladesh has over 95 million mobile phone users, over seven million Facebook users, and 99 percent geographical coverage in voice and data connectivity (International Trade Administration 2016). Avasant (2012) identified Bangladesh as high potential region for scaling up the impact sourcing sector due to the country's success in harnessing skills from the marginalized people in the garment industry. Hence, with existing strong governmental support, initiatives and donor participation in the ICT sector (Chandan 2015), impact sourcing can create significant opportunities for the marginalized communities in the country (Avasant 2012). Nevertheless, key challenges for ImS service providers includes effective recruitment process, viable knowledge on country's ICT environment, training capabilities, retention, and identification of investors as there are a range of possible boundaries for $\mathrm{ImS}$ employability (Pradhan 2017; Kennedy et al. 2013; Accenture 2012).

This paper therefore, reports a study that aims to identify the perceived antecedents of adopting impact sourcing undertakings in Bangladesh for facilitating the recruitment process for potential ImS service providers. The study presents a conceptual framework that will enable BPO and ImS service providers to initiate recruitment for marginalized communities in the country and provide valuable insights to government and ImS practitioners for using ICT as developmental strategy to alleviate poverty.

\section{Literature Review}

As mentioned earlier, impact sourcing defined as a social innovation in BPO and has received limited attention in the literature due its relative newness (Accenture 2012; Sandeep \& Ravishankar 2015; 2016). In the field of ImS research, Malik et al. (2013) assessed the social development impacts on the employees of a commercial outsourcing organization that practices $\operatorname{ImS}$ as its Corporate Social Responsibility (CSR) to provide employment opportunities to marginalized rural women through ICT based work. Additionally, Sandeep and Ravishankar (2015) conducted a qualitative study on seven Indian ImS service providers to develop a process model of the individual-level motivational triggers of impact sourcing entrepreneurship. Selim (2013) summarized a snapshot survey of several innovative approaches to job creation utilized by different ImS providers and highlighted the need for adequate public policies at the framework and human development level. Also, Mikkelsen (2015) conducted a case study on ImS service provider 'Samasource' in evaluating the concept of microwork and confirms the influence of impact sourcing in alleviating poverty. Likewise, Palviaa et al. (2017) utilized a narrative 
research methodology in evaluating participants' beliefs about the role of ICT in socioeconomic development. Furthermore, Kennedy et al. (2013) interviewed both management and BPO workers to understand the impact of ImS employment in Kenya and confirmed the changes in BPO workers' capability and relationship wellbeing.

The literature shows that researchers utilised IT outsourcing models (Heeks, 2014; Sandeep \& Ravishankar 2015; Malik et al. 2013), social entrepreneurship theories (Sandeep \& Ravishankar 2015), developmental theories (ICT4D) (Oprins 2016) and related domain for investigating the impact sourcing phenomenon. Tondeur et al. (2010) stated that research involving ICT knowledge, attitude, adoption decision or usage involves selecting precise facet in order to ensure what key aspects of ICT are more important. In the case of ImS service providers, key factors influencing the decision to operate includes education, geographic location, infrastructural barriers or other issues associated with the ICT environment (Kennedy et al. 2013; Malik et al. 2013). As a result, factors related to technology adoption domain becomes significant in term of assessing key drivers and barriers. Monitor Group (2011) noted that advocates of impact sourcing differ in terms of identifying employable segments. Thus, for some service providers, employing college-educated individuals meets the socio developmental goals, while for others, impact can only be measured through hiring the truly poor and marginalized. For example, Digital Divide Data (DDD) (Malik et al. 2013) aims to create jobs for disadvantaged youth in developing countries. Samasource in contrast, has strong focus on providing female employment through ICT enabled micro work (Mikkelsen, 2015). As different organizations are targeting different segments for providing sourcing opportunities, it is imperative for every ImS organizations to have sound knowledge of the target location and people's understanding towards ICT enabled work or process. Thus, individuals' perceived antecedents is essential for shaping up an adequate ImS sector.

Majority of the ImS research focused on evaluating the social developmental progress of existing ImS providers and no study evaluated Bangladesh from the perspective of Impact Sourcing. Most importantly however, these studies (Avasant 2012; Monitor Group 2011; Kennedy et al. 2013) used country statistics in terms of ICT infrastructure and socioeconomic variables for mapping various ImS models. As a result, there is a significant research gap exist in terms of empirical evidence in identifying the key antecedents to the success of impact sourcing. Existing studies identified the recruitment process in impact sourcing (Monitor Group, 2011) as one of the key challenges faced by ImS providers due to the limited knowledge on host country's IT-BPO environment and Kennedy et al (2013) advocated for specific measures to build capacity.

Although Bangladesh has pioneered in BPO through creating significant amount of employment in its Garment Industry and micro work through the existing micro-credit model, limited attention has been documented in terms of similar activities in the ICT sector. Kennedy et al. (2013) and Avasant (2012) named Bangladesh as a promising ImS destination, however pointed out scarcity of information regarding the IT-BPO environment and recommended further investigation. Majority of the ImS research focused on evaluating the social developmental progress of existing $\operatorname{ImS}$ service providers (e.g. Liew et al. 2014; Hsieh et al. 2008; Monitor Group 2011). Despite being a promising IT-BPO destination Bangladesh has not been properly evaluated in terms of becoming a prospectus destination. Also existing studies on ImS identified Impact Sourcing as still a nascent space that does not enjoy growth rates similar to those of its parent BPO industry due to various infrastructural challenges.

As the range of impact sourcing work is widespread and targeted towards different segments of marginalized communities, an adequate result on key antecedents and ICT knowledge in Bangladesh will facilitate potential ImS providers to take advantage of its human resource pool.

Thus, despite being a highly prospectus target for Impact Sourcing sector, the absence of a proper framework on ImS antecedents in the context of Bangladesh is the key motivation for conducting this research. As a result, this research aims to address this gap through proposing a conceptual framework highlighting the antecedents to effectively develop an ImS sector in the country.

In summary, majority of the ImS studies are somewhat restricted in terms of answering what factors constitutes the development of Impact Sourcing initiatives in Bangladesh and what ICT-based contextual issues can shape the understandings of ImS knowledge and its practices. Providing the absence of an appropriate theoretical model in the ImS studies, a conceptual framework proposed to examine antecedents of adopting Impact Sourcing practices in Bangladesh based on the existing impact sourcing literature. The following section briefly discusses the early methods utilised in the development of the framework. 


\section{Methods}

In the building of the conceptual framework for identifying the antecedents for developing an impact sourcing sector in Bangladesh, data were collected through semi-structured interviews with 23 participants. Different group of informants were invited through purposive sampling method to participate in the interviews from varying ICT related fields in Dhaka and Chittagong Division. The research strategy that has been chosen for this research is that of a single case study of Bangladesh. Within the exploratory nature of the study, an Interpretivist/Constructivist approach has been employed where the reality is viewed as subjective, socially constructed and in constant change (Creswell 2013). The inductive approach for thematic analysis was suitable as it enables to gain necessary knowledge and insight about Bangladesh BPOs and ICT organization through qualitative data, which seems more appropriate to generate knowledge (Yin 2003) out of the case study. An overview of the study participants is presented in table 1 .

\begin{tabular}{llll}
\hline Industry/Fields & Male & Female & Total \\
\hline BPO IT Sourcing & 5 & 1 & 6 \\
Government: ICT & 4 & 2 & 6 \\
ITES (IT enabled Services) & 1 & 2 & 3 \\
Micro Franchising & 2 & 2 & 4 \\
Telecentre & 0 & 1 & 1 \\
NGOs & 2 & 1 & 3 \\
\hline Total & $\mathbf{1 4}$ & $\mathbf{9}$ & $\mathbf{2 3}$ \\
\hline
\end{tabular}

Table 1. Study participants

\section{Results}

The participants provided valuable insights on the factors that may contribute to shaping up the impact sourcing industry in Bangladesh. The participants' view on country's ICT policies, infrastructures, current and future government initiatives in the ICT sector and BPO activities as a whole provided enough data to generate key themes related to the antecedents. Each theme has been further compared and matched with the extent literature on outsourcing, social entrepreneurship, development and adoption literature. Table 2 highlights the key themes examined and their sub-themes.

\begin{tabular}{|c|c|c|c|}
\hline $\begin{array}{l}\text { Key Themes } \\
\text { Examined }\end{array}$ & Literature Blocks & Sub Themes & $\begin{array}{l}\text { Percentage of } \\
\text { Respondents } \\
\text { Endorsing the } \\
\text { Theme }\end{array}$ \\
\hline \multirow{5}{*}{ Outsourcing } & \multirow{4}{*}{ BPO Literature } & Quality Control & $91 \%$ \\
\hline & & Cost & $82 \%$ \\
\hline & & Scalability & $58 \%$ \\
\hline & & Investment Requirement & $44 \%$ \\
\hline & Emerging Theme & Profit Maximization (Survival) & $26 \%$ \\
\hline \multirow{5}{*}{$\begin{array}{l}\text { Social } \\
\text { Entrepreneurship }\end{array}$} & \multirow{4}{*}{ S-E Literature } & Inefficiency & $39 \%$ \\
\hline & & Pro-activeness & $63 \%$ \\
\hline & & Innovation & $74 \%$ \\
\hline & & Individual Influence & $46 \%$ \\
\hline & Emerging Theme & Experience & $25 \%$ \\
\hline \multirow{8}{*}{ ICT4D Factors } & \multirow{8}{*}{ Development Literature } & Supporting Conditions & $49 \%$ \\
\hline & & Training & $56 \%$ \\
\hline & & Awareness & $64 \%$ \\
\hline & & Negative Collaboration & $51 \%$ \\
\hline & & ICT Ease of Access & $78 \%$ \\
\hline & & Retention & $44 \%$ \\
\hline & & Education & $34 \%$ \\
\hline & & Language & $89 \%$ \\
\hline
\end{tabular}


External Factors Adoption Literature

$\begin{array}{ll}\text { Electricity } & 87 \% \\ \text { Community Resistance } & 76 \% \\ \text { Corruption } & 63 \% \\ \text { Slow Internet } & 78 \%\end{array}$

\section{Table 2. Theme Summary}

\section{Conceptual Framework}

Based on the themes generated on table 2, a conceptual framework is created highlighting the key factors which influence the establishment of an ImS industry in Bangladesh.

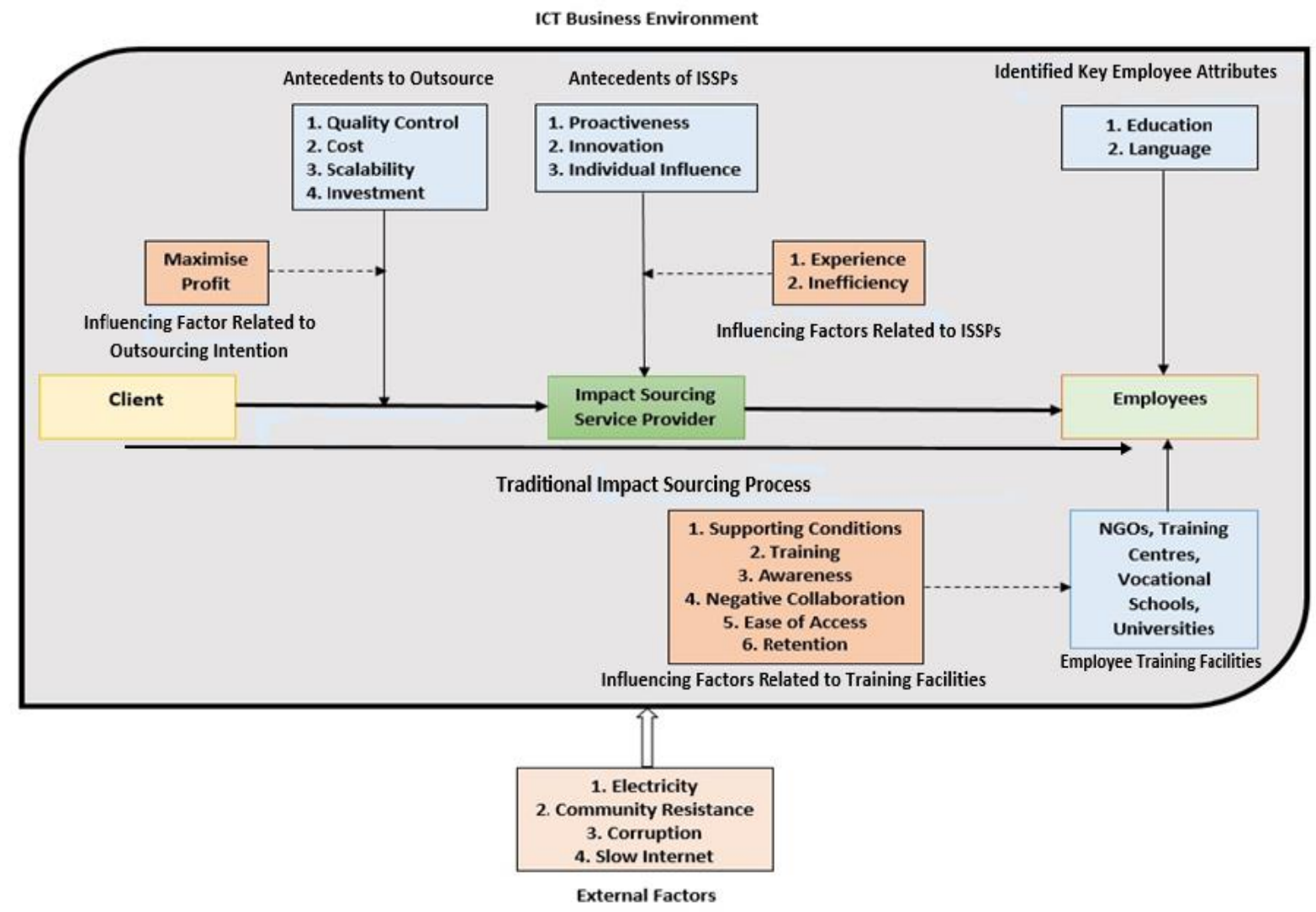

Figure 1: Conceptual Framework

The model highlights that the outsourcing quality control, cost, scalability of projects, requirement of investment is key to shape an adequate BPO environment and ImS sector. However, survival intent (profit maximization) of BPO service providers has been recognized as a key influencing issue. In addition, in terms of ImS service providers, innovation, individual influence and pro-activeness of the service providers has been identified as the key antecedents to successfully employ IS activities in the country. However, efficiency and experience of the service providers plays a critical role to effectively carry out the operations. ICT4D factors involving supporting conditions, training, awareness, collaboration and ease of access has also been recognized by the participants for the establishment for ICT delivery centres. The level of education and language capabilities has been identified as key employee attributes. Lastly, the conceptual framework identified external environmental factors including electricity, community resistance and slow internet as key antecedents for providing a strong ICT infrastructure.

\section{Conclusion \& Implication}

This research-in-progress work identifies the varying antecedents for employing impact sourcing activities in Bangladesh through the proposed conceptual model and as a result, presents ImS service providers the opportunity to expand their socioeconomic development through ICT in highly prospectus Bangladesh. The key antecedents to the success of impact sourcing will enable the ImS service providers 
to fulfil their objectives in terms of hiring multidimensional marginalized people and pursue their business through Bangladeshi resource pool with adequate knowledge and understanding on the disadvantaged communities.

Moreover, the findings of this research is imperative for the Bangladesh government officials because the influencing factors identified in this study can fulfil their aims in addressing the barriers to ICT access and expand ICT knowledge throughout the country. As a result, the government can excel in the 'Digital Bangladesh' initiative by facilitating the disadvantaged rural segment and enable them to gain outsourced employment.

Furthermore, the study will synthesize the existing $\operatorname{ImS}$ theories into the research framework designed for the current study which can add additional insights into the realm of ICT and its impact on socioeconomic factors among marginalized people. The ImS academics, investors and promoters can utilize the findings of this research to extend the existing theoretical knowledge base of impact sourcing research to facilitate further social innovation in outsourcing.

\section{Future Work}

The conceptual model proposed in the study is only the first step in the process of building the first mixed method research in impact sourcing academic discourse. While the interview results provided a conceptual basis for developing key measurement variables, the next step is to validate the model and construct the first tested instrument for assessing impact sourcing adoption decision for the marginalised population. Additionally, continuous secondary and qualitative data collection is in progress for refining the themes, as well as overall improvement of the model. The individuals associated with this research are hopeful that a validated theoretical framework and measurement instrument will provide IS service providers and practitioners with greater understanding in terms of operationalising impact sourcing involving the marginalised communities which can add value not only to the business itself but most importantly, to the society.

\section{References}

Accenture 2012. Exploring the value proposition for impact sourcing, The buyer's perspectives (eds.) Bulloch, G. and Long, J. Available: https://www.rockefellerfoundation.org/app/uploads/ Exploring-the-Value-Proposition-for-Impact-for-Impact-Sourcing.pdf

Avasant, 2012, Incentives \& Opportunities for Scaling the 'Impact Sourcing Sector', September 2012

Beaumont, N., \& Sohal, A. (2004). Outsourcing in Australia. International Journal of Operations \& Production Management, 24(7), 688-700.

Carmel, E., Lacity, M. C., \& Doty, A. (2016). The impact of impact sourcing: Framing a research agenda. In Socially Responsible Outsourcing (pp. 16-47). Palgrave Macmillan, London.

Chandan, H. C. (2015). Creating alignment between corporate sustainability and Global Compact initiatives. In The UN Global Compact: Fair competition and environmental and labour justice in international markets (pp. 37-59). Emerald Group Publishing Limited.

Creswell, J.W. 2013, Research design: Qualitative, quantitative, and mixed methods approaches, Sage publications.

Heeks, R. 2014. Emerging Markets, Information Technology Impact Sourcing, Communication of the $A C M$, Vol. 56, No. 12 December 2013, DOI: 10.1145/2535913

Heeks, R. \& Arun, S. (2010). Social outsourcing as a development tool: The impact of outsourcing IT services to women's social enterprises in Kerala. Journal of International Development: The Journal of the Development Studies Association, 22(4), 441-454.

Hussain, F. \& Mostafa, M. (2016). Digital contradictions in Bangladesh: encouragement and deterrence of citizen engagement via ICTs. Information Technologies \& International Development, 12(2), pp-47.

Irawan, A. (2014). Regional income disparities in Indonesia: measurements, convergence process, and decentralization (Doctoral dissertation, University of Illinois at Urbana-Champaign).

Kennedy, R., Sheth, S., London, T., Jhaveri, E., \& Kilibarda, L. (2013). Impact sourcing: Assessing the opportunity for building a thriving industry. William Davidson Institute and Rockefeller Foundation. 
Kozma, R. B. (2005). National policies that connect ICT-based education reform to economic and social development. Human Technology: An interdisciplinary journal on humans in ICT environments.

Lacity, M.C., Willcocks, L.P. and Solomon, S., 2012. Robust practices from two decades of ITO and BPO research. In Advanced Outsourcing Practice (pp. 1-24). Palgrave Macmillan UK.

Malik, F., Nicholson, B. and Morgan, S., 2013, December. Assessing the social development potential of impact sourcing. In Proceedings of 6th Annual SIG GlobDev Pre ICIS Workshop on ICT in Global Development, Milan, Italy (Vol. 14).

Mikkelsen, L. (2015). Poverty reduction through microwork. A case study of Samasource, [online] http://studenttheses. cbs. dk/handle/10417/5802, access, 8.

Porter, M. E., \& Kramer, M. R. (2011). The big idea: Creating shared value. Harvard Business Review.

Pradhan, S. 2017, 'Analysis of Impact Sourcing by Infusing Social Innovation in Outsourcing for Nepal', in J. Choudrie, M.S. Islam, F. Wahid, J.M. Bass \& J.E. Priyatma (eds), Information and Communication Technologies for Development: 14th IFIP WG 9.4 International Conference on Social Implications of Computers in Developing Countries, ICT4D 2017, Yogyakarta, Indonesia, May 22-24, 2017, Proceedings, Springer International Publishing, Cham, pp. 829-34

Sandeep, M. S., \& Ravishankar, M. N. (2016). Impact sourcing ventures and local communities: a frame alignment perspective. Information Systems Journal, 26(2), 127-155.

Sandeep, M.S. and Ravishankar, M.N., 2015. Social innovations in outsourcing: An empirical investigation of impact sourcing companies in India. The Journal of Strategic Information Systems, 24(4), pp.270-288.

Tondeur, J., Cooper, M., \& Newhouse, C. P. (2010). From ICT coordination to ICT integration: A longitudinal case study. Journal of Computer Assisted Learning, 26(4), 296-306.

Yin, R. K. (2003). Case study research: design and method (3rd).

\section{Copyright}

Copyright: (c) 2018 Saeed Uz Zaman Khan \& Sojen Pradhan. This is an open-access article distributed under the terms of the Creative Commons Attribution-NonCommercial 3.0 Australia License, which permits non-commercial use, distribution, and reproduction in any medium, provided the original author and ACIS are credited. 